\title{
Curdlan and Gellan Gum, Bacterial Gel-Forming Polysaccharides, Exhibit Different Effects on Lipid Metabolism, Cecal Fermentation and Fecal Bile Acid Excretion in Rats
}

\author{
Jun Shimizu,* Masahiro WADA, Toshichika TAKITA \\ and Satoshi InNAmI \\ Department of Nutritional Science, Faculty of Applied Bioscience, \\ Tokyo University of Agriculture, Setagaya-ku, \\ Tokyo 156-8502, Japan
}

(Received August 27, 1998)

\begin{abstract}
Summary The effects of curdlan (CD) and gellan gum (GG), bacteriaproducing polysaccharides, on lipid concentrations of serum and liver, fecal bile acid composition and intestinal fermentation products were studied in rats fed diets containing cellulose powder (CP), CD or GG at $5 \%$ for $4 \mathrm{wk}$. The cecal weight of the $\mathrm{CD}$ group increased significantly as compared to that of the other two groups and the $\mathrm{pH}$ of its contents was significantly low. The gastrointestinal transit time in the GG group was significantly shorter than that in the $\mathrm{CP}$ and $\mathrm{CD}$ groups. No significant inter-group differences were observed in the serum concentrations of total cholesterol and HDL-cholesterol, but a significant decrease was observed in the hepatic total cholesterol concentration of the CD group as compared to that of the CP and GG groups. No significant difference in the total bile acid excretion in feces was observed among the groups, but significantly low values were observed in the proportion of secondary bile acids in the CD group as compared to those of the CP and GG groups. Amounts of short-chain fatty acids (acetic, propionic and butyric acid) and lactic acid in the cecal contents were significantly higher in the CD group than in the other two groups. These results reveal that dietary CD is easily degraded and fermented by intestinal bacteria in the cecum and lowers cholesterol concentration in the liver, while dietary GG shortens the gastrointestinal transit time, suggesting the promotion of evacuation.

Key Words curdlan, gellan gum, short-chain fatty acids, fecal bile acid excretion, cholesterol metabolism
\end{abstract}

* To whom correspondence should be addressed. 
Some bacteria-producing polysaccharides such as xanthan gum, pullulan, curdlan and gellan gum are used as food additives in the food industry. They have structures which cannot be degraded by human digestive enzymes and are considered as a type of dietary fiber. Curdlan (CD), a polysaccharide produced by Alcaligenes faecalis var. myxogenes, is $\beta$-1,3-glucan-linked to straight-chain D-glucose $(1,2)$. Although CD is water-insoluble, it becomes gelled when its aqueous suspension is heated. Gellan gum (GG) produced by Pseudomonas elodea, on the other hand, is a water-soluble polysaccharide consisting of two D-glucose molecules and one each L-rhamnose and D-glucuronic acid molecules (3). CD is used as an improving agent of physical properties and GG as a gelling agent or thickening agent for various food processing. But their physiological functions have not yet been fully studied except for a few reports (4-7).

We previously studied the lipid metabolism in rats fed a hypercholesterolemic diet containing $\mathrm{CD}$ and $\mathrm{GG}$ at $5 \%$ for $2 \mathrm{wk}(8)$. We observed that both substances did not affect the cholesterol concentrations of the serum and liver. But CD caused the cecal weight including contents to increase and the $\mathrm{pH}$ of cecal contents to decrease, while GG increased the number of fecal lumps and shortened the gastrointestinal transit time. We assumed that CD and GG would express different behaviors in the lower digestive tract of rats.

The present study was planned to further clarify the differences in the physiological functions of $\mathrm{CD}$ and GG. Therefore, their effects on the lipid concentrations of serum and liver, fecal bile acid composition and cecal fermentation products were investigated in rats fed cholesterol-free diets.

\section{MATERIALS AND METHODS}

Experimental animals, diet and rearing method. Four-week-old male SpragueDawley rats (Tokyo Experimental Animal, Co., Tokyo) were individually housed in stainless steel apartment cages and reared in a room $\left(23 \pm 1{ }^{\circ} \mathrm{C}\right.$ temperature, $50 \pm 10 \%$ humidity) maintained under a 12-h light/dark cycle (light cycle; 8:00-20:00). The three types of dietary fiber (DF) used for the experiments were cellulose powder (CP, Toyo Roshi Kaisya, Tokyo), curdlan (CD, MW $=7-9 \times 10^{4}$, Takeda Chemical Industries, Osaka) and gellan gum (GG, MW $=6-7 \times 10^{5}$, San-eigen FFI, Osaka). CP was used as the control.

After $7 \mathrm{~d}$ of preliminary rearing on the basal diet (AIN-76), rats were divided into three groups of seven (Experiment 1) or eight rat per group (Experiment 2) and given the following experimental diet $(\mathrm{g} / 100 \mathrm{~g})$ : casein 20.0, DL-methionine 0.3, corn starch 15.0, sucrose 50.0, corn oil 5.0, mineral mixture (AIN-76) 3.5, vitamin mixture (AIN-76) 1.0, choline bitartrate 0.2 and DF 5.0. Water and food were given ad libitum and replaced everyday. After 4 wk on the experimental diets, blood samples were taken from the hearts of animals at 10:00, under sodium pentobarbital anesthesia (50 mg/ $\mathrm{kg}$ body weight), without fasting. Care and use of the rats in the present study followed the guidelines of governmental legislation in Japan (1980). 
Design of Experiment 1: After sampling blood from the heart, the liver was removed and weighed. The cecum was weighed with its contents. The cecal contents were then transferred to $50-\mathrm{mL}$ plastic tubes, homogenized well and the $\mathrm{pH}$ was measured directly using a glass electrode. The cecal tissue was washed with physiological saline $\left(4^{\circ} \mathrm{C}\right)$, blotted on filter paper and weighed. The small intestine and colon plus rectum were measured for their length and processed in the same way as the cecum. Feces were collected for the last $5 \mathrm{~d}$ preceding the end of the experimental period, weighed, freeze-dried and weighed again. After pulverizing in a mill, feces were placed in screw-capped tubes, sealed with nitrogen gas and stored $\left(-30^{\circ} \mathrm{C}\right)$ until analysis. On days 8 and 15 , the animals were starved from 8:00 until 20:00 and then given the diet containing 0.3\% carmine (Wako Pure Chemical Industries, Osaka) as a marker at 20:00. Feces were checked once every $30 \mathrm{~min}$ for presence of the marker, and the time until the presence was first observed was set as the gastrointestinal transit time (mean of two observation times). On day 21, fresh feces were collected, placed in $2 \mathrm{~mL}$ of deionized water, homogenized and the $\mathrm{pH}$ was measured.

Design of Experiment 2: After anesthesia, blood samples were taken from the portal vein and abdominal aorta concurrently. The cecum was immediately removed and weighed. Cecal contents were obtained in the same manner as described in the design of Experiment 1. Portal venous blood and the homogenates of cecal contents were used for determination of ammonia. The remaining homogenates of cecal contents were placed in tubes, frozen with liquid nitrogen and stored at $-80^{\circ} \mathrm{C}$ until analysis of short-chain fatty acids (SCFAs).

Lipid concentration. Blood samples were left standing for $30 \mathrm{~min}$ at room temperature in plastic tubes and then centrifuged $\left(4^{\circ} \mathrm{C}, 1,500 \times \mathrm{g}, 15 \mathrm{~min}\right)$ to obtain serum. Serum concentrations of total cholesterol and HDL-cholesterol were determined with commercial kits (Wako Pure Chemical Industries). Lipids in the liver were extracted by the method of Folch et al (9). Concentrations of total cholesterol and triacylglycerol were determined by the Zak method (10) and Fletcher method (11), respectively. Phospholipid concentration was determined by commercial kits (Wako Pure Chemical Industries).

Fecal bile acids excretion. Bile acids in feces were extracted by the method of Locket and Gallaher (12). Conjugated bile acids were deconjugated by the enzyme method (13) using cholylglycine hydrolase (EC 3.5.1.24, Sigma Chemical, St. Louis, MO, USA). Bile acids were then extracted with diethyl ether under the presence of hydrochloric acid, methylated, trifluoroacetylated and determined by gas-liquid chromatography (Model GC-12A, Shimadzu, Kyoto). For analysis, glass columns $(3.2 \mathrm{~mm} \times 1.6 \mathrm{~m})$ packed with $1.5 \%$ silicone AN-600 on 100/120 mesh Gaschrom Q (Chromatotec, Tokyo) were used (14). As the internal standard, 23-nordeoxycholic acid was used. Standards of bile acids were purchased from Sigma Chemical or Steraloids (Wilton, NH, USA).

Ammonia concentration. Portal venous blood and cecal contents $(\sim 50 \mathrm{mg})$ were immediately added to polyethylene tubes containing deproteinized solution 
(containing sodium tungstate dihydrate and sulfuric acid), mixed and centrifuged $(1,200 \times g, 5 \mathrm{~min})$. Ammonia concentrations in both supernatants were determined spectrophotometrically (15).

SCFAs and lactic acid in the cecal contents. SCFAs were determined by partially modifying the method of Deschner et al (16). After thawing, about $0.1 \mathrm{~g}$ of the cecal contents was transferred to $1.5 \mathrm{~mL}$ polyethylene tubes, weighed, added with $0.05 \mathrm{~mL}$ of $40 \mathrm{~mm}$ 2-ethyl- $n$-butyric acid (the internal standard) and $0.75 \mathrm{~mL}$ of $25 \%$ metaphosphoric acid, and homogenized by ultrasonication for $1 \mathrm{~min}$ at $4^{\circ} \mathrm{C}$. Homogenate was held overnight at $4^{\circ} \mathrm{C}$, and then centrifuged, $8,000 \times g$ for $30 \mathrm{~min}$ at $4^{\circ} \mathrm{C}$. Supernatant was filtered through a $0.45-\mu \mathrm{m}$ filter (Dismic-13 Cellulose Nitrate, Toyo Roshi Kaisha, Tokyo). The sample was analyzed by gas-liquid chromatography (Model GC-12A, Shimadzu) equipped with a glass column $(3.2 \mathrm{~mm} \times 1.6 \mathrm{~m})$ packed with $10 \% \quad \mathrm{SP}-1200 / 1 \% \quad \mathrm{H}_{3} \mathrm{PO}_{4} \quad$ on $80 / 100$ mesh Chromosorb W AW (Superlco, PA, USA). The concentration of lactic acid in the cecal contents was measured with a D-Lactic/L-Lactic acid kit (BoehringerMannheim, Mannheim, Germany).

Statistical analyses. Values are expressed as mean \pm SE. After processing with one-way ANOVA $(p<0.05)$, the significant differences among the diet groups were analyzed by Duncan's multiple range test (17) $(p<0.05$, SPSS version 7.5.1J for Windows, SPSS Japan, Tokyo).

\section{RESULTS}

\section{Body weight gain and food intake}

Table 1 shows changes in body weight and food intake in Experiment 1 . No significant differences in body weight were observed between the CD and GG groups and the CP group. During the periods of day 0 to day 21 and day 0 to day 28 , food intake of the CD group showed significantly low values $(p<0.05)$ compared with that of the CP group (control). The food efficiency ratio (mean $\pm \mathrm{SE}$ ) was

Table 1. Effect of curdlan and gellan gum on body weight and total food intake in rats (Experiment 1$){ }^{1}$

\begin{tabular}{|c|c|c|c|c|c|c|}
\hline \multirow{2}{*}{$\begin{array}{l}\text { Feeding } \\
\text { period } \\
\text { (d) }\end{array}$} & \multicolumn{3}{|c|}{ Body weight (g) } & \multicolumn{3}{|c|}{ Total food intake $(\mathrm{g})$} \\
\hline & Cellulose & Curdlan & Gellan gum & Cellulose & Curdlan & Gellan gum \\
\hline 0 & $138 \pm 2$ & $137 \pm 2$ & $137 \pm 1$ & 0 & 0 & 0 \\
\hline 7 & $192 \pm 2$ & $194 \pm 4$ & $195 \pm 2$ & $135 \pm 2$ & $129 \pm 3$ & $132 \pm 3$ \\
\hline 14 & $253 \pm 3$ & $253 \pm 5$ & $255 \pm 3$ & $298 \pm 5$ & $275 \pm 6$ & $286 \pm 7$ \\
\hline 21 & $321 \pm 5$ & $311 \pm 5$ & $318 \pm 5$ & $475 \pm 9^{a}$ & $430 \pm 10^{\mathrm{b}}$ & $452 \pm 13^{\mathrm{ab}}$ \\
\hline 28 & $377 \pm 7$ & $362 \pm 8$ & $363 \pm 7$ & $658 \pm 14^{a}$ & $595 \pm 16^{\mathrm{b}}$ & $625 \pm 19^{\mathrm{ab}}$ \\
\hline
\end{tabular}

${ }^{1}$ Mean \pm SE $(n=7)$ : values in the same row not sharing a common superscript letter are significantly different at $p<0.05$. 
Table 2. Effect of curdlan and gellan gum on characteristics of digestive tracts, fecal weight and gastrointestinal transit time (GTT) in rats (Experiment 1). ${ }^{1}$

\begin{tabular}{cccc}
\hline Items & Cellulose & Curdlan & Gellan gum \\
\hline Small intestine & & & \\
Weight (g) & $7.52 \pm 0.30$ & $8.95 \pm 0.81$ & $7.92 \pm 0.37$ \\
Length (cm) & $124 \pm 2$ & $126 \pm 2$ & $123 \pm 1$ \\
Cecum & & & \\
Weight (g) & $0.50 \pm 0.02^{\mathrm{a}}$ & $1.10 \pm 0.11^{\mathrm{b}}$ & $0.45 \pm 0.04^{\mathrm{a}}$ \\
Contents (g) & $2.11 \pm 0.12^{\mathrm{a}}$ & $4.37 \pm 0.43^{\mathrm{b}}$ & $1.86 \pm 0.14^{\mathrm{a}}$ \\
pH & $7.35 \pm 0.12^{\mathrm{a}}$ & $6.12 \pm 0.21^{\mathrm{b}}$ & $7.47 \pm 0.14^{\mathrm{a}}$ \\
Colon plus rectum & & & \\
Weight (g) & $1.08 \pm 0.05^{\mathrm{a}}$ & $1.39 \pm 0.09^{\mathrm{b}}$ & $1.36 \pm 0.08^{\mathrm{b}}$ \\
Length (cm) & $19.7 \pm 0.7$ & $20.9 \pm 0.4$ & $20.1 \pm 0.5$ \\
Feces & & & \\
Lumps (number/d) & $16.3 \pm 0.7^{\mathrm{a}}$ & $12.4 \pm 1.6^{\mathrm{a}}$ & $32.7 \pm 1.6^{\mathrm{b}}$ \\
Wet weight (g/d) & $2.20 \pm 0.08^{\mathrm{a}}$ & $1.39 \pm 0.17^{\mathrm{b}}$ & $2.42 \pm 0.19^{\mathrm{a}}$ \\
Dry weight $(\mathrm{g} / \mathrm{d})$ & $1.87 \pm 0.06^{\mathrm{a}}$ & $0.88 \pm 0.09^{\mathrm{b}}$ & $1.60 \pm 0.09^{\mathrm{c}}$ \\
Moisture $(\%)$ & $15.2 \pm 0.7^{\mathrm{a}}$ & $35.5 \pm 1.9^{\mathrm{b}}$ & $33.1 \pm 1.9^{\mathrm{b}}$ \\
pH & $7.62 \pm 0.12^{\mathrm{a}}$ & $5.69 \pm 0.13^{\mathrm{b}}$ & $7.23 \pm 0.10^{\mathrm{c}}$ \\
GTT (min) & $684 \pm 12^{\mathrm{a}}$ & $673 \pm 31^{\mathrm{a}}$ & $514 \pm 23^{\mathrm{b}}$ \\
\hline
\end{tabular}

${ }^{1}$ Mean $\pm \operatorname{SE}(n=7)$ : values in the same row not sharing a common superscript letter are significantly different at $p<0.05$.

$0.36 \pm 0.00$ in the $\mathrm{CP}$ group, $0.38 \pm 0.01$ in the $\mathrm{CD}$ group and $0.36 \pm 0.01$ in the $\mathrm{GG}$ group, indicating no inter-group differences.

Experiment 2 showed a tendency similar to Experiment 1 (data not shown), but none of the items showed significant differences among groups.

\section{Characteristics of the digestive tract, fecal weight and gastrointestinal transit time}

Table 2 shows the results of Experiment 1. The weight of small intestine in the CD group was not significantly different $(p<0.05)$ from those in the CP and GG groups. The length was substantially the same in all the groups. The cecal weight of the $\mathrm{CD}$ group increased to approximately twice that of the $\mathrm{CP}$ group. On the other hand, no difference was observed between the GG group and the CP group. The weight of cecal contents in the $\mathrm{CD}$ group also significantly increased $(p<0.05)$ as compared to that in the CP and GG groups. The cecal contents of the $\mathrm{CD}$ group looked highly viscous, but that of the GG group appeared to be mostly gelled particles. There was no difference in the $\mathrm{pH}$ of the cecal contents between the CP group and GG group, but that of the CD group was significantly lower $(p<0.05)$ than that of the other two groups. The weight of colon plus rectum was significantly higher $(p<0.05)$ in the $\mathrm{CD}$ and $\mathrm{GG}$ groups than in the $\mathrm{CP}$ group, but the length was not different among the groups.

The number of fecal lumps in the GG group increased significantly $(p<0.05)$ 
Table 3. Effect of curdlan and gellan gum on weights of cecum and colon plus rectum, and ammonia concentrations of portal vein blood, and cecal contents in rats (Experiment 2). ${ }^{1}$

\begin{tabular}{cccc}
\hline Items & Cellulose & Curdlan & Gellan gum \\
\hline Cecum & & & \\
Weight $(\mathrm{g})$ & $0.46 \pm 0.01^{\mathrm{a}}$ & $1.11 \pm 0.06^{\mathrm{b}}$ & $0.57 \pm 0.02^{\mathrm{a}}$ \\
$\quad$ Contents $(\mathrm{g})$ & $2.11 \pm 0.12^{\mathrm{a}}$ & $4.37 \pm 0.43^{\mathrm{b}}$ & $1.86 \pm 0.14^{\mathrm{a}}$ \\
pH & $7.22 \pm 0.14^{\mathrm{a}}$ & $6.12 \pm 0.09^{\mathrm{b}}$ & $7.45 \pm 0.10^{\mathrm{a}}$ \\
Colon plus rectum & $1.09 \pm 0.03^{\mathrm{a}}$ & $1.32 \pm 0.11^{\mathrm{b}}$ & $1.37 \pm 0.04^{\mathrm{b}}$ \\
$\quad$ Weight (g) & $183 \pm 13$ & $210 \pm 7$ & $208 \pm 7$ \\
Ammonia concentration & $24.8 \pm 2.5^{\mathrm{a}}$ & $15.6 \pm 1.5^{\mathrm{b}}$ & $12.2 \pm 1.8^{\mathrm{b}}$ \\
$\quad$ Portal vein blood $(\mu \mathrm{g} / \mathrm{dL})$ & $51.1 \pm 6.0^{\mathrm{a}}$ & $63.0 \pm 9.8^{\mathrm{a}}$ & $24.1 \pm 4.0^{\mathrm{b}}$ \\
$\quad$ Cecum ( $\mu \mathrm{g} / \mathrm{g}$ contents) & & \\
$\quad(\mu \mathrm{g} /$ contents) & & & \\
\hline
\end{tabular}

${ }^{1}$ Mean \pm SE $(n=8)$ : values in the same row not sharing a common superscript letter are significantly different at $p<0.05$.

as compared to that in the $\mathrm{CP}$ and $\mathrm{CD}$ groups. The shape was varied and more or less elongated in the CD group, while it was normally elliptical in the CD and GG groups, and the lump size, although it was not measured, looked to be smaller in the GG group than in the CP group. Wet and dry fecal weights per day of the $\mathrm{CD}$ group decreased significantly $(p<0.05)$ as compared to those of the $\mathrm{CP}$ and $\mathrm{GG}$ groups. The fecal moisture in the $\mathrm{CD}$ and $\mathrm{GG}$ groups was significantly increased $(p<0.05)$ as compared to that in the CP group. No diarrhea was observed.

The gastrointestinal transit time in the GG group was significantly shortened $(p<0.05)$ as compared to that in the CP and CD groups, but there was no relation observed between the gastrointestinal transit time and fecal weight.

Table 3 shows the results of Experiment 2. Substantially similar results as Experiment 1 were observed in respect of the cecal weight and the weight and $\mathrm{pH}$ of the cecal contents. Ammonia concentration of the portal vein blood in the $C D$ and $\mathrm{GG}$ groups was not different from that in the $\mathrm{CP}$ group. Ammonia concentration per gram of the cecal contents in the $\mathrm{CD}$ and $\mathrm{GG}$ groups decreased significantly $(p<0.05)$ as compared to that in the CP group. As for the amount of ammonia in entire cecal contents, no significant difference was observed between the $\mathrm{CP}$ group and CD group, but the GG group showed a significant decrease $(p<0.05)$ as compared to the other two groups.

\section{Lipid concentration in serum and liver}

Table 4 shows the results of Experiments 1 and 2. In both experiments, there were no significant inter-group differences observed in the total cholesterol and HDL-cholesterol concentrations in serum. The liver weight did not differ among groups. Total cholesterol concentration of the liver in the CD group decreased 
Table 4. Effect of curdlan and gellan gum on serum and liver lipid concentrations and liver weight in rats. ${ }^{1}$

\begin{tabular}{lccc}
\hline Items & Cellulose & Curdlan & Gellan gum \\
\hline Experiment $1(n=7)$ & & & \\
$\quad$ Serum & & & \\
$\quad$ Total cholesterol $(\mathrm{mg} / \mathrm{dL})$ & $129 \pm 7$ & $123 \pm 6$ & $130 \pm 8$ \\
$\quad$ HDL-cholesterol $(\mathrm{mg} / \mathrm{dL})$ & $71.0 \pm 6.7$ & $72.4 \pm 5.4$ & $62.0 \pm 8.5$ \\
Liver & & & \\
$\quad$ Weight $(\mathrm{g})$ & $17.9 \pm 0.6$ & $16.3 \pm 0.5$ & $16.9 \pm 0.7$ \\
$\quad$ Total cholesterol $(\mathrm{mg} / \mathrm{g})$ & $3.62 \pm 0.33^{\mathrm{a}}$ & $2.65 \pm 0.10^{\mathrm{b}}$ & $3.56 \pm 0.33^{\mathrm{a}}$ \\
$\quad$ Triacylglycerol $(\mathrm{mg} / \mathrm{g})$ & $54.7 \pm 7.3^{\mathrm{a}}$ & $31.5 \pm 4.2^{\mathrm{b}}$ & $45.8 \pm 5.7^{\mathrm{b}}$ \\
$\quad$ Phospholipids $(\mathrm{mg} / \mathrm{g})$ & $26.4 \pm 1.6$ & $24.5 \pm 1.0$ & $27.5 \pm 1.6$ \\
& & & \\
Experiment 2 $(n=8)$ & & & \\
$\quad$ Serum & $130 \pm 10$ & $114 \pm 5$ & $123 \pm 8$ \\
$\quad$ Total cholesterol $(\mathrm{mg} / \mathrm{dL})$ & $73.5 \pm 3.8$ & $66.6 \pm 5.5$ & $75.1 \pm 4.9$ \\
$\quad$ HDL-cholesterol $(\mathrm{mg} / \mathrm{dL})$ & & & \\
Liver & $18.5 \pm 0.8$ & $18.0 \pm 0.4$ & $17.4 \pm 0.8$ \\
$\quad$ Weight $(\mathrm{g})$ & $3.68 \pm 0.31^{\mathrm{a}}$ & $2.86 \pm 0.16^{\mathrm{b}}$ & $3.59 \pm 0.23^{\mathrm{a}}$ \\
$\quad$ Total cholesterol $(\mathrm{mg} / \mathrm{g})$ & $62.3 \pm 6.3^{\mathrm{a}}$ & $41.9 \pm 4.9^{\mathrm{b}}$ & $53.0 \pm 6.6^{\mathrm{b}}$ \\
$\quad$ Triacylglycerol $(\mathrm{mg} / \mathrm{g})$ & $18.8 \pm 0.9$ & $18.5 \pm 0.7$ & $19.7 \pm 0.8$ \\
$\quad$ Phospholipids $(\mathrm{mg} / \mathrm{g})$ & &
\end{tabular}

${ }^{1}$ Mean \pm SE: values in the same row not sharing a common superscript letter are significantly different at $p<0.05$.

significantly $(p<0.05)$ as compared to that in the CP and GG groups. Triacylglycerol concentration in the liver in the CD group decreased significantly $(p<0.05)$ as compared to that in the $\mathrm{CP}$ group, but the decrease seen in the GG group was not significant. Phospholipid concentration remained unchanged.

\section{Fecal bile acid excretions}

Table 5 shows the results of Experiment 1. Lithocholic acid was significantly higher $(p<0.05)$ in the CD group than in the other two groups. No significant difference was observed in deoxycholic acid. Significantly higher $(p<0.05)$ values of $\alpha$-muricholic acid and $\beta$-muricholic acid were observed in the CD group than in the $\mathrm{CP}$ and GG groups, but hyodeoxycholic acid in the CD group was significantly lower $(p<0.05)$ than that in the $\mathrm{CP}$ and $\mathrm{GG}$ groups. In the $\mathrm{CP}$ and $\mathrm{GG}$ groups, the major bile acid was hyodeoxycholic acid, while in the CD group, it was $\beta$-muricholic acid; both acids accounting for about half of the total amount. No inter-group difference was significant in the total bile acid excretion. The proportion of secondary bile acids to total bile acids was significantly lower $(p<0.05)$ in the $\mathrm{CD}$ group than in the $\mathrm{CP}$ and GG groups. 
Table 5. Effect of curdlan and gellan gum on fecal bile acids and ratio of secondary bile acids to total bile acids in rats (Experiment 1). ${ }^{1}$

\begin{tabular}{llll}
\hline \multicolumn{1}{c}{ Bile acid } & Cellulose & Curdlan & Gellan gum \\
\hline & & $(\mathrm{mg} / \mathrm{d})$ \\
Lithocholic acid & $0.22 \pm 0.01^{\mathrm{a}}$ & $0.57 \pm 0.10^{\mathrm{b}}$ & $0.24 \pm 0.07^{\mathrm{a}}$ \\
Deoxycholic acid & $0.43 \pm 0.04$ & $0.30 \pm 0.04$ & $0.43 \pm 0.07$ \\
$\alpha$-Muricholic acid & $0.04 \pm 0.01^{\mathrm{a}}$ & $0.26 \pm 0.05^{\mathrm{b}}$ & $0.12 \pm 0.05^{\mathrm{a}}$ \\
Hyodeoxycholic acid & $2.54 \pm 0.16^{\mathrm{a}}$ & $0.19 \pm 0.08^{\mathrm{b}}$ & $2.09 \pm 0.31^{\mathrm{a}}$ \\
Cholic acid & $0.05 \pm 0.01^{\mathrm{a}}$ & $0.18 \pm 0.03^{\mathrm{b}}$ & $0.09 \pm 0.03^{\mathrm{a}}$ \\
$\beta$-Muricholic acid & $0.11 \pm 0.02^{\mathrm{a}}$ & $2.02 \pm 0.34^{\mathrm{b}}$ & $0.45 \pm 0.14^{\mathrm{a}}$ \\
$\omega$-Muricholic acid & $0.04 \pm 0.01^{\mathrm{a}}$ & $0.05 \pm 0.01^{\mathrm{a}}$ & $0.10 \pm 0.02^{\mathrm{b}}$ \\
Total & $4.04 \pm 0.24$ & $3.91 \pm 0.54$ & $3.83 \pm 0.56$ \\
Secondary/total bile acids & $0.80 \pm 0.02^{\mathrm{a}}$ & $0.28 \pm 0.04^{\mathrm{b}}$ & $0.76 \pm 0.04^{\mathrm{a}}$ \\
\hline
\end{tabular}

${ }^{1}$ Mean \pm SE $(n=7)$ : values in the same row not sharing a common superscript letter are significantly different at $p<0.05$.

Table 6. Effect of curdlan and gellan gum on amounts of short-chain fatty acids (SCFAs) and lactic acid in cecal contents of rats (Experiment 2). ${ }^{1}$

\begin{tabular}{lccc}
\hline \multicolumn{1}{c}{ Items } & Cellulose & Curdlan & Gellan gum \\
\hline & & $(\mu \mathrm{mol} / \mathrm{g}$ cecal contents $)$ & \\
Acetic acid & $38.9 \pm 4.1^{\mathrm{a}}$ & $50.7 \pm 2.9^{\mathrm{b}}$ & $32.0 \pm 1.5^{\mathrm{a}}$ \\
Propionic acid & $16.7 \pm 1.1^{\mathrm{a}}$ & $20.8 \pm 1.7^{\mathrm{b}}$ & $9.6 \pm 0.7^{\mathrm{c}}$ \\
Butyric acid & $8.6 \pm 1.1^{\mathrm{a}}$ & $12.0 \pm 1.2^{\mathrm{b}}$ & $6.6 \pm 0.5^{\mathrm{a}}$ \\
Total SCFAs & $72.8 \pm 6.5^{\mathrm{a}}$ & $95.6 \pm 3.9^{\mathrm{b}}$ & $54.9 \pm 2.8^{\mathrm{c}}$ \\
Lactic acid & $1.53 \pm 0.7^{\mathrm{a}}$ & $6.86 \pm 1.39^{\mathrm{b}}$ & $0.61 \pm 0.11^{\mathrm{a}}$ \\
& & & \\
& & $(\mu \mathrm{mol} / \mathrm{cecal}$ contents $)$ & $62 \pm 5^{\mathrm{a}}$ \\
Acetic acid & $80 \pm 9^{\mathrm{a}}$ & $199 \pm 14^{\mathrm{b}}$ & $19 \pm 2^{\mathrm{a}}$ \\
Propionic acid & $35 \pm 3^{\mathrm{a}}$ & $83 \pm 10^{\mathrm{b}}$ & $13 \pm 1^{\mathrm{a}}$ \\
Butyric acid & $18 \pm 3^{\mathrm{a}}$ & $49 \pm 9^{\mathrm{b}}$ & $97 \pm 9^{\mathrm{a}}$ \\
Total SCFAs & $139 \pm 16^{\mathrm{a}}$ & $337 \pm 30^{\mathrm{b}}$ & $1.2 \pm 0.2^{\mathrm{a}}$ \\
Lactic acid & $3.0 \pm 0.4^{\mathrm{a}}$ & $25.8 \pm 4.2^{\mathrm{b}}$ & \\
\hline
\end{tabular}

${ }^{1}$ Mean $\pm \mathrm{SE}(n=8)$ : values in the same row not sharing a common superscript letter are significantly different at $p<0.05$.

\section{SCFAs and lactic acid in the cecal contents}

Table 6 shows the amounts of SCFAs and lactic acid in the cecal contents in Experiment 2. The CD group revealed a significantly high value $(p<0.05)$ in both the concentration and total amount of SCFAs as compared to the CP and GG groups. The GG group values tended to be lower than the CP group. The concentration and amount of lactic acid in the CD group was significantly higher 
$(p<0.05)$ than those in the CP and GG groups. No difference was observed between the $\mathrm{CP}$ group and $\mathrm{GG}$ group.

\section{DISCUSSION}

We observed enlargement of the cecum and lowering of $\mathrm{pH}$ in the cecal contents in rats fed the CD diet. Similar results have been observed under feeding conditions of cholesterol-free (7) or -added diets (8). These observations may indicate that CD is easily degraded and fermented by intestinal bacteria in the cecum as in the case with many water-soluble dietary fibers. Lowered $\mathrm{pH}$ of the cecal contents is recognized to be attributable mainly to increased concentrations of organic acids such as lactate and succinate (18). In the CD group, the lactic acid concentration in the cecal contents was actually elevated significantly as compared to the CP and GG groups. On the other hand, in the GG group, the $\mathrm{pH}$ of the cecal contents was significantly higher and the total SCFA amount was significantly lower than that of the CD group. Edwards and Eastwood (6) reported that GG had little effect on the cecal SCFA. Thus, GG is considered to be hardly degraded and fermented by intestinal bacteria.

Many water-soluble dietary fibers are characterized by their tendency to become easily fermented by intestinal bacteria (19) and extend the gastrointestinal transit time. However, we observed that the gastrointestinal transit time in the GG group was significantly shorter than that in the other two groups. This phenomenon is supported by the paper of Tetsuguchi et al (7). GG is known to become highly viscous when dissolved in water and to easily form gels under the condition of low concentration of cations. As the cecal contents in the GG group consisted of gel-like particles, it is considered that GG administered in powder form became gelled in the rat stomach and went down to the cecum in the same state. It is assumed that one reason for the resistance against degradation of GG by bacteria is attributable to such physical properties of the cecal contents. However, non-degradation of GG in the large intestine may perhaps be caused essentially by the absence of bacteria by which the sugar chain of GG could be cleaved. Thus, we presume that the shortening of gastrointestinal transit time by GG feeding may contribute to relieving constipation and to creating smooth evacuation.

The ammonia concentration in the cecal contents of the CD group markedly decreased as compared to that of the CP group. This might be due to the dilution effect accompanied by the increased weight of the cecal contents, as the total amount of ammonia in the contents was not different between the CD group and CP group. In the $\mathrm{CD}$ group, ammonia concentration in the portal venous blood was assumed to rise as the ammonia-absorbing mucosal surface increased accompanying enlargement of the cecum. However, the concentration in the CD group was not different from that in the CP group. Castell and Moore (20) reported that ammonia becomes ionized by the increase of SCFAs in the large intestine and is less likely to become absorbed. Accordingly, the reason for no rise in the ammonia con- 
centration in portal venous blood in the $\mathrm{CD}$ group might be attributable to the increased amount of SCFAs in the cecal contents. This does not necessarily reflect directly the elevation of ammonia in the cecum of the CD group, because ammonia is known to be utilized by intestinal bacteria as a nitrogen source for proliferation. The decrease of total amount of ammonia in the cecal contents of the GG group might be attributed to the decreased bacterial growth in the cecum on the account of less utilization of $\mathrm{GG}$ as a carbon source.

In this experiment, we observed a significantly lower total cholesterol concentration in the liver, but no inter-group changes in serum cholesterol concentration. The theory that the effects of dietary fibers on cholesterol metabolism are mediated by increased steroid excretion into feces (21) has been quite influential so far, but there are also reports that no relevance is observed between the two $(22,23)$. In the present study, the excretion of bile acids into feces was not different between the $\mathrm{CP}$ group and $\mathrm{CD}$ group. Therefore, hepatic cholesterol $7 \alpha$-hydroxylase activity is not likely to be increased in the CD group. On the other hand, there is a report that SCFAs produced by intestinal bacteria in the large intestine participate in affecting the cholesterol metabolism (24). This is because propionic acid among SCFAs was observed to lower cholesterol synthesis in an in vitro experiment using cultured hepatocytes. The amount of propionic acid in the cecal contents of the $\mathrm{CD}$ group was significantly higher than that of the CP and GG groups. Topping and Pant (25) pointed out that a comparison is difficult because the concentration of propionic acid differs in in vitro and in vivo experiments. However, there exists undeniably a relation between cholesterol metabolism and cecal fermentation products, because SCFAs are constantly being produced by intestinal bacteria in the rat cecum. SCFAs are also reported to increase the blood flow in the mucosa of the intestinal tract (26). Since enlargement of the cecum was observed in the CD group, we assume that a considerable amount of SCFAs might be absorbed. Accordingly, it is considered that the effect of SCFAs on hepatic cholesterol concentration is certainly not negligible.

Bile acids are the final metabolites of cholesterol, and secondary bile acids converted by intestinal bacteria are considered to promote mutagenicity in the colon (27). Many intestinal bacteria have $7 \alpha$-dehydroxylase which catalyzes the conversion of primary bile acids to secondary bile acids, and the activity of this enzyme is clearly inhibited below pH 6.5 (28). Thornton (29) assumed that the intestinal environment is improved by the acidification of intestinal contents and feces by the mechanism which inhibits formation and activation of carcinogens derived from bile acids and cholesterol. An increase in secondary acids, particularly of lithocholic acid and deoxycholic acid, is considered to increase cancer risk as the results of studies on humans (30) and in vitro studies (31). The main bile acid in the feces of the $\mathrm{CD}$ group was $\beta$-muricholic acid, which is the primary bile acid of rat. In this group, the ratio of secondary bile acids/total bile acids was significantly lowered, suggesting that CD inhibited the formation of secondary bile acids owing to a lower $\mathrm{pH}$ in the cecum. In the $\mathrm{CD}$ group, the fecal excretion of lithocholic 
acid was observed to be significantly high. However, lithocholic acid is a highly hydrophobic monohydroxy bile acid and may precipitated under acidic conditions. Therefore, it develops cancer-promoting activity only when it is dissolved in the large intestine. It is not clear whether the increased excretion of lithocholic acid in the CD group was due to accelerated conversion from chenodeoxycholic acid to lithocholic acid by intestinal bacteria or to accelerated excretion into feces by lowered re-absorption.

Based on the foregoing, dietary $\mathrm{CD}$ is degraded and fermented by intestinal bacteria in the cecum, and thereby may act to improve the intestinal environment and lower cholesterol concentration in the liver. Dietary GG shortens the gastrointestinal transit time, suggesting that it promotes evacuation. A study of the relationship between the degradation mechanism of $\mathrm{CD}$ and intestinal flora is also warranted.

We wish to express our appreciation to Takeda Chemical Industries Ltd. for providing curdlan and gellan gum for this study.

\section{REFERENCES}

1) Harada T, Masuda M, Fujimori K, Maeda I. 1966. Production of a firm, resilient gel-forming polysaccharide by a mutant of Alcaligenes faecalis var. myxogenes 10C 3 . Agric Biol Chem 30: 196-198.

2) Harada T, Misaki A, Saito H. 1968. Curdlan: A bacterial gel-forming $\beta$-1,3-glucan. Arch Biochem Biophys 124: 292-298.

3) Maurice DM, Srinivas SP. 1992. Use of fluorometry in assessing the efficacy of a cation-sensitive gel as an ophthalmic vehicle: comparison with scintigraphy. $J$ Pharm Sci 81: 615-619.

4) Tsuji E, Tsuji K, Suzuki S. 1975. Effects of various polysaccharides on serum and liver cholesterol levels in cholesterol-fed rats. Eiyogaku Zasshi (Jpn J Nutr) 33: 273-281.

5) Anderson DMW, Brydon WG, Eastwood MA. 1987. The dietary effects of gellan gum in humans. Food Addit Contam 5: 237-249.

6) Edwards CA, Eastwood MA. 1995. Caecal and faecal short-chain fatty acids and stool output in rats fed on diets containing non-starch polysaccharides. Br J Nutr 73: 773-781.

7) Tetsuguchi M, Nomura S, Katayama M, Sugawa-Katayama Y. 1997. Effects of curdlan and gellan gum on the surface structure of intestinal mucosa in rats. J Nutr Sci Vitaminol 43: $515-527$.

8) Shimizu J, Innami S. 1997. Effects of curdlan and gellan gum on lipid concentrations of serum and liver, fecal steroid excretion and gastrointestinal function in rats fed a hypercholesterolemic diet. Tokyo Nogyo Daigaku Nogaku Syuho (J Agric Sci Tokyo Nogyo Daigaku) 42: 41-47.

9) Folch J, Lees M, Stantley GHS. 1957. A simple method for the isolation and purification of total lipids from animal tissues. $J$ Biol Chem 226: 497-509.

10) Zak B. 1957. Simple rapid microtechnic for serum total cholesterol. Am J Clin Pathol 27: $583-588$.

11) Fletcher MJ. 1968. A colorimetric method for estimating serum triglycerides. Clin Chim Acta 22: 393-397.

12) Locket PL, Gallaher DD. 1989. An improved procedure for bile acid extraction and purification and tissue distribution in the rat. Lipids 24: 221-223.

Vol 45, No 3, 1999 
13) Lepage G, Roy CC, Weber AM. 1981. Separation of sulfated from non-sulfated serum bile acids without the use of Sephadex columns. $J$ Lipid Res 22: 705-711.

14) Uchida K, Takase H, Nomura Y, Takeda K, Takeuchi N, Ishikawa Y. 1984. Changes in biliary and fecal bile acids in mice after treatments with diosgenin and $\beta$-sitosterol. $J$ Lipid Res 25: 236-245.

15) McCullough H. 1967. The determination of ammonia in whole blood by a direct colorimetric method. Clin Chim Acta 17: 297-304.

16) Deschner EE, Ruperto JF, Lupton JR, Newmalk HL. 1990. Dietary butyrate (tributyrin) does not enhance AOM-induced colon tumorigenesis. Cancer Lett 52: 79-82.

17) Duncan DB. 1955. Multiple range and multiple F tests. Biometrics 11: 1-42.

18) Hoshi S, Sakata T, Mikuni K, Hashimoto H, Kimura S. 1994. Galactosylsucrose and xylosylfructoside alter digestive tract size and concentrations of cecal organic acids in rats fed diets containing cholesterol and cholic acid. $J$ Nutr 124: 52-60.

19) Jacobs LR. 1990. Influence of soluble fibers on experimental colon carcinogenesis. In: Dietary Fiber: Chemistry, Physiology, and Health Effects (Kritchevsky D, Bonfield C, Anderson JW, eds), p 389-401. Plenum Press, New York and London.

20) Castell DO, Moore EW. 1971. Ammonia absorption from the human colon. Gastroenterology 60: 33-42.

21) Arjmandi BH, Ahn J, Nathani S, Reeves RD. 1992. Dietary soluble fiber and cholesterol affect serum cholesterol concentration, hepatic portal venous short-chain fatty acid concentrations and fecal sterol excretions in rats. $J$ Nutr 122: 246-253.

22) Anderson JW, Deakins DA, Bridges SR. 1990. Soluble fiber; Hypocholesterolemic effects and proposed mechanisms. In: Dietary Fiber; Chemistry, Physiology, and Health Effects (Krichevsky D, Bonfield C, Anderson J, eds), p 339-363. Plenum Press, New York and London.

23) Nishimura N, Nishikawa H, Kiriyama S. 1993. Ileorectostomy or cecectomy but not colectomy abolishes the plasma cholesterol-lowering effect of dietary beet fiber in rats. J Nutr 123: 1260-1269.

24) Wright RS, Anderson JW, Bridges SR. 1990. Propionate inhibits hepatocyte lipid synthesis. Proc Soc Exp Biol Med 195: 26-29.

25) Topping DL, Pant I. 1995. Short-chain fatty acids and hepatic lipid metabolism: experimental studies. In: Physiological and Clinical Aspects of Short-Chain Fatty Acids (Cummings JH, Rombeau JL, Sakata T, eds), p 495-507. Cambridge University Press, London.

26) Motensen FV, Nielsen H. 1995. In vivo and in vitro effects of short-chain fatty acids on intestinal blood circulation. In: Physiological and Clinical Aspects of Short-Chain Fatty Acids (Cummings JH, Rombeau JL, Sakata T, eds), p 391-400. Cambridge University Press, London.

27) Reddy BS, Watanabe K, Weisburger JH, Wynder EL. 1977. Promoting effect of bile acids in colon carcinogenesis in germ-free and conventional F344 rats. Cancer Res 37: 3238-3242.

28) Aries V, Hill MJ. 1970. Degradation of steroids by intestinal bacteria. II. Enzymes catalysing the oxidoreduction of the $3 \alpha-, 7 \alpha-$ and $12 \alpha$-hydroxy groups in cholic acid, and the dehydroxylation of the 7-hydroxyl group. Biochim Biophys Acta 202: 535-543.

29) Thornton JR. 1981. High colonic pH promotes colorectal cancer. Lancet 8229: 1081-1083.

30) Owen RW, Henly PJ, Thompson MH, Hill MJ. 1986. Steroids and cancer: fecal bile acid screening for early detection of cancer risk. J Steroid Biochem 24: 391-394.

31) Wilpart M, Mainguet P, Maskens A, Roberfroid M. 1983. Mutagenicity of 1,2-dimethylhydrazine towards Salmonella typhimurium, co-mutagenic effect of secondary biliary acids. Carcinogenesis 4: 45-48. 